\title{
Through-the-scope transpyloric stent placement improves symptoms and gastric emptying in patients with gastroparesis
}

\section{Case 1 \\ $\nabla$}

A 23-year-old woman was evaluated in clinic for diabetic gastroparesis. At the time of our evaluation, she was symptomatic despite a regimen consisting of domperidone, esomeprazole, ondansetron, duloxetine, and promethazine. Previous attempts using erythromycin and metoclopramide were both unsuccessful and limited by side effects. She continued to undergo frequent hospitalization, with four admissions to our facility plus numerous admissions to her local hospital. A 4-hour solid state gastric emptying scintigraphy study revealed only $47 \%$ emptying at 4 hours. Gastric stimulation was declined by her insurance company and she therefore proceeded with transpyloric stent placement ( $\mathbf{F i g} \mathbf{1} \mathbf{a}-\mathbf{c}$ ).

The patient reported complete resolution of her daily morning nausea and cessation of all vomiting after stent placement. Her repeat 4-hour solid-state gastric scintigraphy, obtained 1 month after stent placement, was normal with $93 \%$ emptying at 4 hours. Approximately 1 month after placement she developed recurrent symptoms in the context of stent migration that resolved after stent removal and replacement. She remains well 115 days after stent placement.

\section{Case 2}

\section{$\nabla$}

A 15-year-old boy was referred with chronic nausea and vomiting. A 4-hour solid gastric scintigraphy was markedly abnormal and notable with $46 \%$ retention at 4 hours. Trials of erythromycin, metoclopramide, domperidone, and promethazine were unsuccessful. Following discussions, he underwent transpyloric stent placement and immediately noted marked improvement following the procedure. A repeat 4-hour gastric scintigraphy study was markedly improved with normal emptying parameters at 1 and 2 hours and mildly abnormal emptying (11\% re- tention) at the 4-hour measurement. The patient remains well 122 days after stent placement.

\section{Case 3 \\ $\nabla$}

A 45-year-old man was referred for management of idiopathic gastroparesis. His main symptoms included early satiety and chronic nausea. A 90-minute gastric emptying study at another center had reported only $12 \%$ emptying at 90 minutes, with an estimated gastric emptying halftime of over 400 minutes. Previous medical trials of erythromycin, metoclopramide, and domperidone were not successful at sufficiently alleviating his symptoms. He underwent transpyloric stent placement. Subsequently, he had complete symptom resolution and has been able to eat ad lib without nausea or early satiety. A repeat gastric emptying scintigraphy obtained at the same center as the original test was normal and showed $33 \%$ emptying at 60 minutes, 59\% emptying at 90 minutes, and a calculated emptying half-time of 77 minutes. The patient remains asymptomatic 174 days after stent placement.

All placed stents were the double-layered fully-covered Niti-S self-expandable metallic stent (TaeWoong Medical, Seoul, Korea). Our data suggest that transpyloric stent placement improves symptoms associated with impaired gastric emptying as well as intrinsically improving emptying parameters.

\section{Endoscopy_UCTN_Code_TTT_1AO_2AZ}

Competing interests: Dr Clarke is a consultant for ProStrakan and Wyeth. Dr Khashab is a consultant for Boston Scientific. Dr Kalloo is a founding member, equity holder, and consultant for Apollo Endosurgery. All other authors have no competing interests.
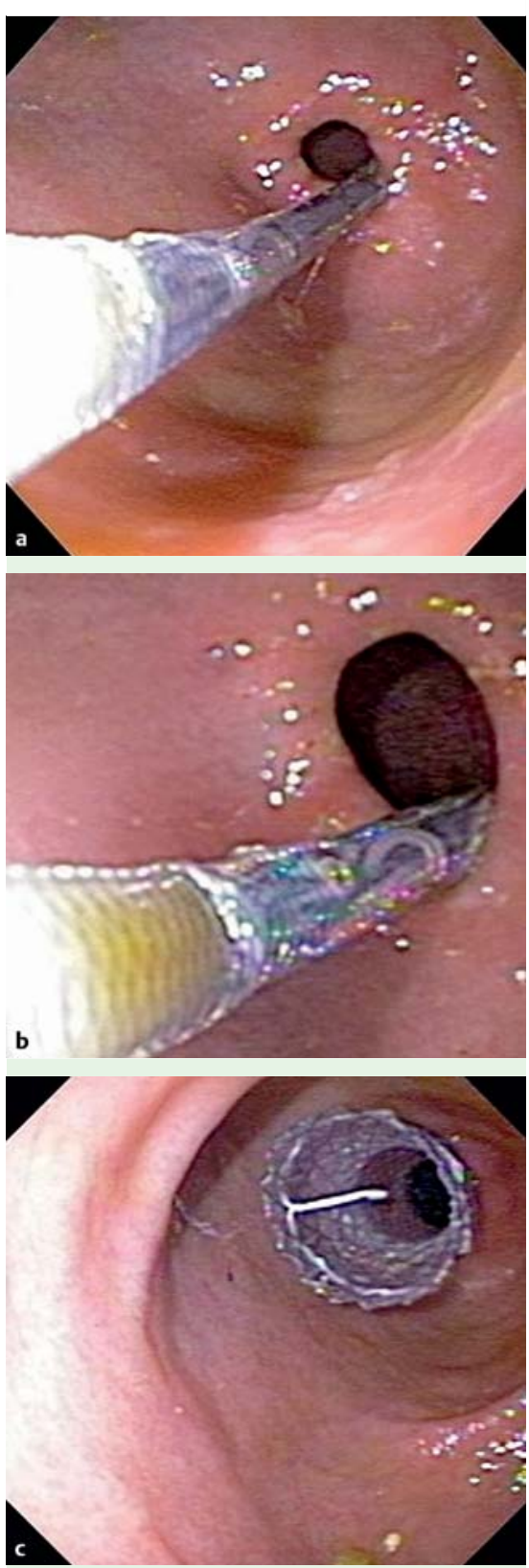

Fig. 1 Placement of self-expandable metallic stent across the pyloric channel. a The delivery system is placed across the pylorus. $\mathbf{b}$ The stent is deployed under endoscopic guidance without fluoroscopy and with the aid of the yellow endoscopic marker at the proximal end of the stent. c The stent is fully deployed in the transpylori position with its proximal end in the gastric antrum. 


\section{J. O. Clarke, R. Z. Sharaiha,}

A. Kord Valeshabad, L. A. Lee,

A. N. Kalloo, M. A. Khashab

Department of Medicine and Division of Gastroenterology and Hepatology, The Johns Hopkins Medical Institutions, Baltimore, Maryland, USA
Bibliography

DOI http://dx.doi.org/ 10.1055/s-0032-1326400 Endoscopy 2013; 45: E189-E190

(C) Georg Thieme Verlag KG

Stuttgart · New York

ISSN 0013-726X
Corresponding author

\section{J. O. Clarke, MD}

\section{Room 425}

Department of Medicine and Division of Gastroenterology and Hepatology Johns Hopkins Hospital

1830 E. Monument Street Baltimore, MD 21205

USA

Fax: +1-410-614-7631

john.clarke@jhu.edu 